\title{
Modelo de integração dos dispositivos móveis na Educação Primária. Criação de uma Aplicação para a sua utilização educativa no quinto ano ${ }^{1}$
}

\begin{abstract}
Resumo
A aparição do tablet digital supôs uma grande evolução na hora de levar a cabo certas práticas na aula. Estas oferecem-nos inúmeras particularidades funcionais como pode ser a portabilidade, a conexão, a capacidade ou a simplicidade de utilização, convertendose num recurso educativo atraente. Sob este olhar, a experiência inovadora que se apresenta teve por objetivos: a) integrar no quinto ano da educação primária, a utilização de dispositivos móveis (SmartPhone e Tablet), como recursos para trabalhar determinados conteúdos curriculares, e, b) conhecer quais são as verdadeiras utilizações que este tipo de estudantes fazem destes dispositivos. Para isso, criou-se uma App com certos conteúdos específicos que foram utilizados como extensão dos conteúdos curriculares. O método de investigação foi o desenho experimental pré-teste - pósteste. Como resultado, comprovou-se que, os estudantes do quinto ano de educação primária, não utilizam os dispositivos móveis com um uso educativo; mas, valoriza-se muito positivamente que a sua utilização, dentro e fora da aula, produza uma melhoria das competências das TIC neste tipo de alunos.
\end{abstract}

Palavras-chave: Mobile learning [aprendizagem móvel]; App [Aplicação]; Caso de estudo.

\section{María Barroso Megías}

Graduada em Educação pela

Universidade de Castilla-La

Mancha - Espanha

mary_5_cobeja@hotmail.com

\section{Felipe Gértrudix Barrio}

Professor do Departamento de Didática da Expressão Musical, Plástica e Corporal da Universidade de Castilla-La Mancha - UCLM. Doutor em

Criatividade Aplicada pela Universidade Complutense de Madrid - Espanha felipe.gertrudix@uclm.es

\section{Para citar este artigo:}

MEGÍAS, María Barroso; BARRIO, Felipe Gértrudix. Modelo de integração dos dispositivos móveis na Educação Primária. Criação de uma Aplicação para a sua utilização educativa no quinto ano. Revista Linhas. Florianópolis, v. 17, n. 33, p. 111-134, jan./abr. 2016.

\section{DOI: $10.5965 / 1984723817332016111$}

http://dx.doi.org/10.5965/1984723817332016111

\footnotetext{
${ }^{1}$ É uma ação pertencente ao grupo CIBERIMAGINARIO-UCLM.

* Optou-se por manter a grafia original do texto.
} 


\title{
Model integration of mobile devices in Primary Education. Creating an App for educational use in the fifth grade
}

\begin{abstract}
The emergence of digital tablet has meant a great evolution in conducting certain practices in the classroom. They provide us many functional features such as portability, connectivity, and simplicity of use, becoming it an engaging and educational resource. Under this perspective, we present an innovative experience whose objectives were: a) integrate the use of mobile devices (smartphone and tablet) in the fifth year of primary school as a resource to work certain curricular content and b) know the real uses that these students are making of these devices. For that, it was created an App with some specific contents that has been used as an extension of course contents. The method used in this research was an experimental pretest-posttest design. Finally, as a result it has been proven that students in the fifth year of primary school do not use mobile devices for educational use; although its use, inside and outside the classroom, it is viewed favorably and produces an improvement in ICT skills in this student body
\end{abstract}

Keywords: Mobile learning; App; Case study. 


\section{Introdução}

A associação das TIC com educação permitiu agilizar ou facilitar a transmissão dos conteúdos por meios eletrónicos mais atraentes para os escolares, mas é necessário reavaliar a relação existente entre o docente-estudante-conhecimento e a ferramenta computacional (RUIZ PALMERO e SÁNCHEZ RODRÍGUEZ, 2005), sendo o docente o verdadeiro artifício do motor de mudança, um novo docente entendido como um profissional competente e comunicado, crítico com a sua prática docente e "que pode ajudar os seus alunos a aprender a aprender" (FERNÁNDEZ MUÑOZ, 2003, págs. 5-6), que deve completar-se com uma série de atitudes positivas e abertas ante a Sociedade da Informação e as TIC, predisposição diante da aprendizagem contínua e uma atuação "prudente na utilização das TIC" (INTEF)

Por vezes, introduziram-se as TIC na aula sem se ter resolvido previamente os problemas reais que poderiam colocar-se na hora de levar a cabo a implementação destas ferramentas na aula, os benefícios que poderão dar à relação docente - estudante e levar a situações desfavoráveis (CAÑELLAS, 2006), sendo necessário desenvolver competências de autêntica alfabetização digital para alcançar uma produtividade maior, melhoria na qualidade do trabalho e inovação tecnológica (ÁLVAREZ \& O'SULLIVAN, 2015).

Fazendo um bom uso das TIC, poderemos beneficiar de todas as vantagens que nos são oferecidas graças a estas. Deste modo, a incorporação de tecnologias na aula, deve realizar-se com o pensamento de introduzir os escolares nas novas mudanças que vivemos, aproximando-os a novas formas de aprendizagem, induzi-los a novos conhecimentos e dotá-los das destrezas necessárias à convivência em sociedade. Neste sentido, fazemos eco das ideias que, no seu momento, Juan Jesús Baena (2008) nos propôs, ao afirmar que se realmente se deseja que estas tecnologias sejam um instrumento educativo, a primeira coisa a fazer-se é dar um grande avanço pedagógico, e isto engloba tanto a mudança no papel de professor, como no papel de estudante. Assim, conseguir-se-á um maior nível de motivação e interesse por parte dos alunos porque trabalha-se através de computadores, quadros digitais interativos, tablets..., e o papel do 
professor mudará sendo o melhor guia de aprendizagem dos seus alunos (INSTITUTO CRANDON, 2015; ALBION, TONDEUR, FORKOSH-BARUCH, e PEERAER, 2015).

\subsection{Integração de recursos tecnológicos na aula}

Desde há várias décadas, integramos tipos diferentes de recursos tecnológicos na sala. Desde o correio electrónico, como meio de comunicação entre pais - professores alunos; a utilização do quadro digital interativo (PDI) como meio de aprendizagem de determinados conteúdos por parte dos alunos (GALLEGO, CACHEIRO e DULAC, 2009), ou a utilização de sistemas LMS e contendores web para a aprendizagem, todos eles foram facilitadores, para estudantes, para docentes e também para pais e/ou tutores (ÁLVAREZ, 2010).

Evidentemente, o principal instrumento de integração nas aulas foi o computador, o qual constituiu o motor de arranque do que hoje conhecemos como aulas de TIC. Este ofereceu um grande apoio ao sistema educativo e chegou a considerar-se como um guia do processo de ensino-aprendizagem.

$\mathrm{Na}$ atualidade, no contexto escolar, são inúmeros os instrumentos que vamos encontrando na sala para responder às necessidades da sociedade em que estamos imersos. Os mais utilizados são: computadores, quadros digitais, páginas web, correios electrónicos, programas didáticos... Ao mesmo tempo, graças a diversos recursos e aplicações web, podem levar-se a cabo atividades como as realizadas com programas como HotPotatoes, JClic, Webquest, Cazas del tesoro, Wikis, entre outros recursos (GÉRTRUDIX e BALLESTEROS, 2014).

\subsection{A aprendizagem através de dispositivos m-learning: tablets e telemóveis}

$\mathrm{Na}$ literatura encontramos diferentes autores que definem o conceito de Mobile Learning. As características principais que deve abranger vêm definidas como: uma experiência educativa em qualquer lugar e a qualquer momento (HOFMANN, 2006), na qual as aulas devem contar com Internet e quadros digitais (MARQUÉS, 2013), telefones 
móveis, telemóveis, i-Pods (HERNÁN MORA, 2010), que sejam facilitadores do processo de ensino-aprendizagem no contexto escolar (VÁZQUEZ-REINA, 2011), e que permita trabalhar em diferentes ambientes nos quais o professor possa colaborar e produzir diversas atividades: “M-learning [é] o suporte digital das atividades de aprendizagem adaptativas, investigativas, comunicativas, colaborativas e produtivas em locais remotos, propõe uma vasta variedade de ambientes nos quais o professor pode operar" (LAURILLARD, 2007, p. 173).

Neste tipo de aprendizagem, deve-se distinguir entre tecnologia e metodologia, porque os dispositivos digitais são instrumentos úteis que nos permitem "fazer mais coisas", embora não garantam as aprendizagens. Por outro lado, as aprendizagens dependem da atividade mental que cada aluno realize. Por isso, deve mediar-se e observar-se que os novos recursos requerem a utilização de novas metodologias, para que os alunos se sintam motivados e inspirados a levar a sua aprendizagem corretamente. Então, qual o papel dos dispositivos digitais na sala? Que autonomia de utilização os alunos têm na sala?

\subsection{Vantagens e problemáticas associadas ao m-learning}

Como já comentamos, existe uma série de características implícitas no modelo mlearning que acentua uma série de vantagens sobre outros métodos de aprendizagem. Entre estas vantagens estão: a) comunicação e colaboração online b) a portabilidade c) a multifuncional, e a d) aprendizagem autónoma. Além destas potencialidades intrínsecas, o m-learning é potenciador no desenho de recursos multimédia, fomentando a curiosidade do discente, mercê à capacidade de desenvolvimento didático que garante a multitude de aplicações existentes, conseguindo uma maior motivação e implicação no estudante e uma melhoria das suas aprendizagens, favorecendo a sua capacidade de reflexão, de criação, etc.

Apesar destas vantagens, existem também problemas associados ao m-learning, distinguindo os de carácter técnico e os de carácter pedagógico. 


\section{a) Carácter técnico:}

- existem uma grande obsolência dos dispositivos digitais, provocando incompatibilidades entre dispositivos e arquivos, e

- ainda existem problemas de ligação à Internet nos centros escolares.

b) Carácter pedagógico:

- existe pouca responsabilidade e dedicação por parte do docente,

- requer uma maior disponibilidade entre os docentes para criar e procurar recursos, e transmiti-los na sala.

- requer uma maior formação nos docentes das competências técnicas-funcionais que permitam levar a cabo uma utilização segura e correta deste tipo de dispositivos (MARQUÈS GRAELLS, 2013).

Tabela 1. Vantagens e problemáticas associadas ao m-learning
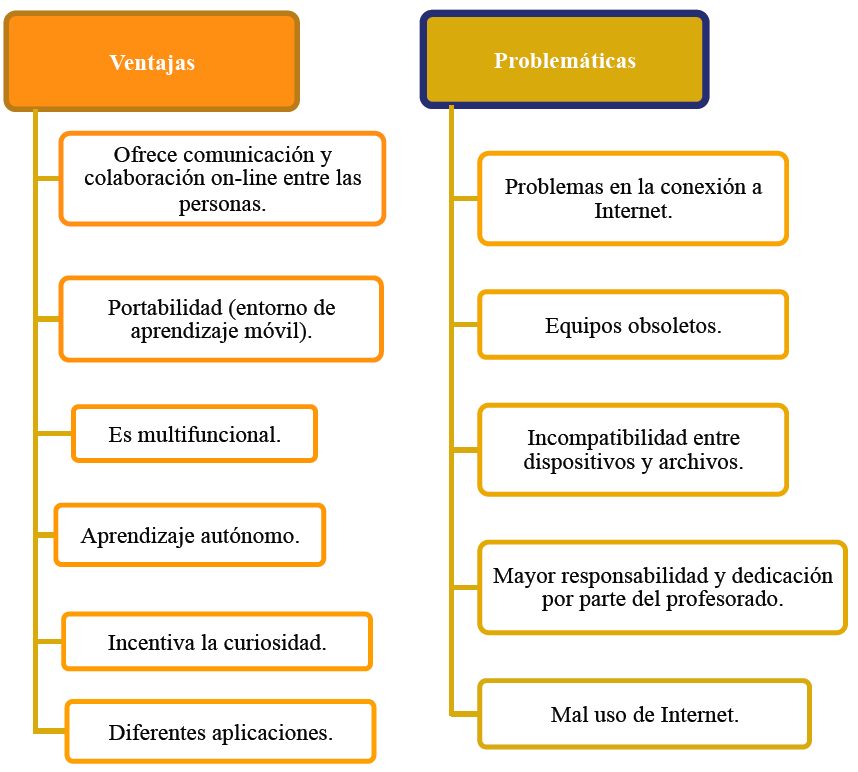

Fonte: elaboração própria.

\subsection{Uso das Aplicações como ferramentas de aprendizagem na aula}

Na maioria dos casos dos professores que introduziram as TIC na sala, asseguram a existência de um aumento na motivação e na responsabilidade dos seus alunos (ZUGOWITKI, 2012), especialmente naqueles com um desenvolvimento lento de maturidade, mas tudo isto também está condicionado pela metodologia utilizada pelo 
docente e pelos materiais que este utilize (LÓPEZ ESCRIBANO, 2007).

Dentro deste âmbito desenvolveram-se atividades com inúmeros dispositivos tecnológicos para a melhoria de diversos conteúdos devido a que existem, relativamente ao âmbito das Apps, inúmeros tipos de Apps com várias características e peculiaridades.

Por outro lado, temos que ter em conta que as TIC, e em concreto as Apps, não são um instrumento homogéneo (CLARO, 2010) e a sua disponibilidade "não é por si mesma uma garantia de que se utilizem de forma ativa para o ensino e para a aprendizagem" (VALENCIA \& SAID, 2014, p. 364), mas que, bem ao contrário, tem que se atender à grande variedade que estas oferecem tendo em conta que algumas serão mais benéficas para algumas disciplinas ou conceitos do que outras. Existem investigações que estudaram a utilização do software de simulações e modelos demostrando ser melhores na aprendizagem das ciências e das matemáticas, contra o desenvolvimento da linguagem e das destrezas de comunicação que foram favorecidas com a utilização dos processadores de texto e dos sistemas de comunicação online através do correio eletrónico (TRUCANO, 2005; KULIK, 2003).

Em relação à utilização de recursos móveis, é importante destacar que a sua implementação por si só não modifica um desenvolvimento significativo de capacidades cognitivas, requer uma boa planificação docente onde a inter-relação de atividades de carácter presencial com recursos m-learning, e "a união da aprendizagem formal com a informal e permanente, é como se pode conseguir o desenvolvimento das capacidades cognitivas superiores nos estudantes" (RAMOS, HERRERA y RAMÍREZ, 2010, p. 209)

Ainda assim, encontramos alguns inconvenientes relativamente à implementação das Apps como método de aprendizagem de determinados conteúdos porque, segundo Cabero (2007), as TIC apresentam uma série de limitações como as seguintes: o acesso e os recursos necessários por parte do estudante, a necessidade de uma infra-estrutura administrativa específica e o pessoal técnico de apoio, o custo da aquisição dos equipamentos, a necessidade de adaptar-se a novos métodos de aprendizagem e a falta de experiência educativa na sua consideração como meio de formação. Esta situação pode causar experiências negativas nos alunos, porque precisa-se que se dê inúmeros 
aspectos para que se desenvolva corretamente o trabalho e o resultado seja positivo relativamente à aprendizagem dos alunos a que se refere.

\section{Objetivos e hipóteses da investigação}

Como objeto de estudo, colocou-se a criação de uma App no contexto de uma sala do $5^{\circ}$ ano da Primária para a aprendizagem de conteúdos históricos relacionados com a Idade Média.

A partir deste objeto foram identificados os seguintes objetivos de investigação:

a) Conhecer o grau de penetração da utilização do SmartPhone ou Tablet entre as crianças que estudam no $5^{\circ}$ ano da primária.

b) Saber que tipo de Apps utilizam as crianças do $5^{\circ}$ ano da primária.

c) Conhecer o motivo pelo qual as crianças do $5^{\circ}$ ano da primária utilizam os telemóveis do tipo SmartPhone.

d) Comprovar que atitude declaram as crianças que estudam o 5 ano da primária diante do uso didático de uma App para o conhecimento de um conteúdo histórico.

Em consequência, as hipóteses formuladas ficaram como se segue:

1. Um número muito elevado de crianças de 10 e 11 anos utilizam SmartPhone ou Tablet.

2. Habitualmente, as crianças de 10 e 11 anos costumam utilizar aplicações para jogar ou conversar com os seus amigos e amigas.

3. As crianças de 10 e 11 anos utilizam os dispositivos móveis principalmente para uso lúdico e de comunicação (conversar, jogos, etc.)

4. O uso educativo dos dispositivos móveis em crianças de 10 e 11 anos é inexistente.

5. Existe uma atitude positiva entre as crianças de 10 e 11 anos diante do uso de aplicações educativas em dispositivos móveis. 
Tabela 1. Relação de objetivos e hipóteses

\begin{tabular}{|cc|}
\hline Objetivos & Hipóteses \\
\hline $\mathbf{1}$ & 1 \\
\hline $\mathbf{2}$ & 2 \\
\hline 3 & 3 e 4 \\
\hline 4 & 5 \\
\hline
\end{tabular}

\section{Metodologia \\ 3.1. Descrição do contexto da investigação}

O presente projeto levou-se a cabo com estudantes do $5^{\circ}$ ano da educação primária de um colégio público situado numa povoação da comarca da Sagra na província de Toledo (Espanha).

A partir do desenvolvimento de uma unidade didática com conteúdos históricos sobre a Idade Média, criou-se uma aplicação com o objetivo de facilitar aos alunos e alunas deste nível educativo, uma visão diferente desta época histórica. A aplicação utilizou-se como complemento de uma atividade complementar, onde os conteúdos trabalhados de uma forma vivencial, se centraram em algumas das Lendas medievais de Toledo mais conhecidas. Além da aplicação servir como complemento à excursão levada a cabo pelo tutor, onde anterior se trabalharam estas lendas de forma vivencial.

A criação da App serviu para conhecer os interesses e a utilidade que as crianças do $5^{\circ}$ ano da primária dão às aplicações que têm nos seus SmartPhones ou Tablets.

\subsection{Concepção e desenvolvimento da aplicação utilizada no projeto}

Em seguida, detalhamos o processo que se levou a cabo para a elaboração da aplicação utilizada no projeto de inovação docente.

Entre as possibilidades que apareciam no princípio, decidiu-se encaminhar a criação da App por um estilo de programação como o APP INVENTOR. A dita eleição foi motivada por vários fatores: 
- Aplicação simples e dinâmica que permite a programação em nuvem sem necessidade de instalar nenhum tipo de aplicação e intuitivo.

- Não necessita ter grandes conhecimentos em programação. Trata-se de uma ferramenta muito potente e inovadora pelas suas funções múltiplas e pela sua simplicidade do momento de aplicá-la dentro da App (por quebra-cabeças que se unem) e através do desenho das janelas, ou seja, sem ter que realizar uma programação com código tipo HTML 5.

Ainda assim, devido ao tipo de atividades didáticas planificadas viu-se a necessidade de utilizar outro tipo de aplicação mais complexa, na qual se pudesse personalizar a interface com o objetivo de obter uma fatura final mais profissional e adaptada às necessidades particulares do projeto. Para isso, desenvolveu-se um ambiente de programação Android com Eclipse.

Tabela 2. Principais ecrãs das versões das aplicações criadas segundo o tipo de programação

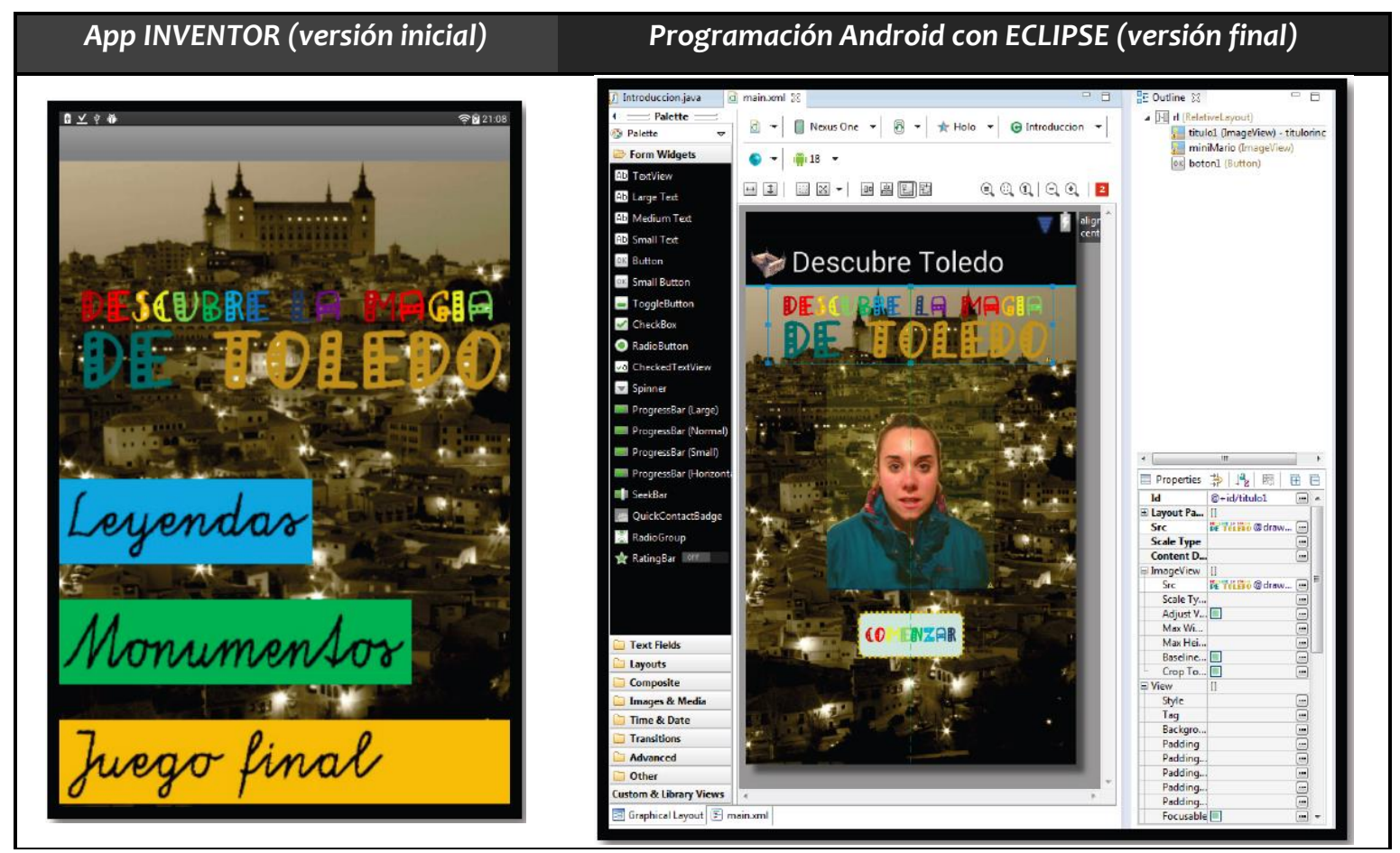

Fonte: elaboração própria a partir da captura de ecrã das diferentes aplicações 


\subsection{População e amostragem}

Em relação à população, considerou-se todos os estudantes que estudam no $5^{\circ}$ ano da primária no centro. O total de alunos e alunas são 68.

A amostra que se tomou corresponde aos estudantes da sala experimental com um $n^{\circ}$ total de 23 alunos e alunas.

\subsection{Procedimento e instrumentos de recolha de informações}

A investigação está dentro do paradigma do quantitativo e do desenho quaseexperimental, enquadrado no modo de Casos de Estudo. Escolheu-se o questionário como ferramenta de investigação para a recolha de dados.

Seguiram-se três fases no desenho da investigação:

A. Pré-teste. Questionário (pré) que foi concluído por toda a população; ou seja, por todos os estudantes do nível do quinto ano da primária. Isto foi feito com propósito duplo: a) conhecer qual o tipo de dispositivos móveis utilizam (SmartPhone vs Tablet, e b) conhecer quais as utilizações que dão a este tipo de dispositivos móveis. As variáveis da investigação atenderam a três dimensões relacionadas com os três primeiros objetivos:

- Dimensão 1 (objetivo 1). Grau de penetração (quem utiliza),

- Dimensão 2 (objetivo 2). O quê. Que tipo de Apps

- Dimensão 3 (objetivo 3). Utilizações

B. Fase experimental. A implementação de uma série de atividades com a aplicação criada "ex profeso" para esta investigação com os estudantes da sala experimental; ou seja, com os alunos e alunas da amostra selecionada.

C. Pós-teste. Questionário (pós), que só o concluíram os estudantes da sala experimental (amostra), com a finalidade de conhecer o grau de satisfação e implicação que os alunos têm relativamente às atividades educativas mediante a utilização de SmartPhones e 
Tablets. As perguntas do questionário atenderam as variáveis de investigação correspondentes à dimensão relacionada com um quarto dos objetivos:

- Dimensão 4 (objetivo 4). Atitude diante da utilização de dispositivos móveis

\subsection{Técnicas e instrumentos de recolha de informações}

Escolheu-se o questionário como ferramenta de investigação para a recolha de dados. Tal e como nos diz Francesc Martínez (2002), a elaboração de um questionário é necessária "no momento em que se decide obter informações diretas de uma quantidade considerável de pessoas para conhecer aspectos concretos das mesmas" (p. 19).

Como já indicamos, criaram-se dois questionários:

- Pré-teste. Dito questionário é composto por 9 perguntas, misturando-se perguntas abertas, fechadas, dicotómicas e de escolha múltipla, tratando-se de uma técnica quantitativa (ver anexo 1).

- Pós-teste. Tratando-se do mesmo tipo de perguntas do anterior questionário, é composto por 10 perguntas (ver anexo 2).

O motivo pelo qual se levaram a cabo ditos questionários foi, por tratar-se de uma observação indireta, os dados não foram obtidos diretamente, mas precisam de algum elemento (questionário) para ter certezas sobre a informação.

\section{Resultados}

Em seguida, detalham-se os resultados mais relevantes do processo de análise e interpretação dos dados, segundo as dimensões examinadas: 


\subsection{Dimensão 1. Grau de penetração dos dispositivos móveis}

78\% dos sujeitos questionados declaram dispor de um Tablet, enquanto $64 \%$ possuem um telemóvel SmartPhone. Esta diferença é devida, em parte, ao preconceito existente entre os pais sobre os perigos na utilização do telemóvel em relação ao Tablet, em especial neste tipo de crianças nestas idades (10-11 anos). Em relação à disponibilidade de dados nos SmartPhones, só $46 \%$ dos estudantes a têm.

\subsection{Dimensão 2. Quando e que tipo de Apps utilizam}

O maior uso que os estudantes fazem dos dispositivos móveis e das suas aplicações é durante os finais de semana. 54\%, mais da metade dos sujeitos questionados, utilizam estes dispositivos unicamente durante os finais de semana, enquanto $21 \%$ usamnos diariamente. Nesta apreciação, pode ver-se como os pais desconfiam sobre se estes dispositivos são utilizados positivamente e se ajudam os seus filhos e filhas nas tarefas escolares e no estudo, o que faz com que estes dispositivos sejam considerados meios de distração. $24 \%$ dos alunos e alunas utilizam o SmartPhone ou o Tablet durante os finais de semana e diariamente, portanto, pode destacar-se que são utilizadores habituais desta tecnologia, seja de forma educativa, ou de forma de entretenimento ou diversão.

Gráfico 1. Tipos de Apps que os alunos e alunas utilizam

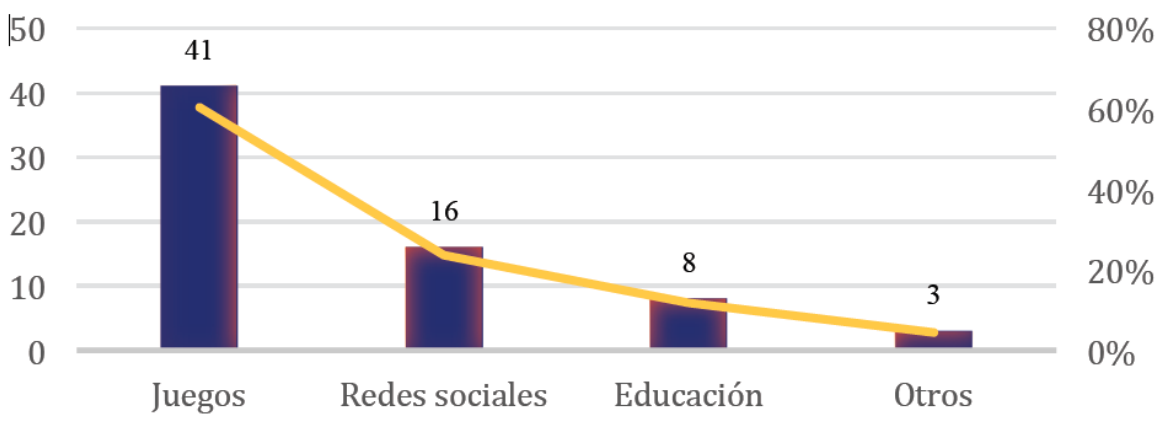

Em relação à utilização como ferramenta para a aprendizagem, 43\% dos alunos e alunas manifesta que utiliza o SmartPhone ou o Tablet para estudar diversos conteúdos 
das matérias que se tratam na sala. Neste caso, estudar engloba levar a cabo trabalhos, pesquisa de informações ou qualquer aspecto relacionado com a utilização do SmartPhone ou do Tablet e referido ao âmbito educativo. Também podemos comprovar que, com uma percentagem muito semelhante (40\%), muitos deles e delas não utilizam estes dispositivos tecnológicos para o estudo, mas pode acontecer que os vejam como um meio de ócio ou não compatível com o seu âmbito de estudo. Por último, e com uma percentagem inferior (18\%), encontramos sujeitos que, por vezes, utilizam o SmartPhone ou o Tablet para o estudo, entendendo estes como um meio complementar de outros recursos.

Por último, para a pergunta "Que tipo de aplicações utilizas?", 60\% respondeu que são as aplicações de jogos, como Angry Birds, Candy Crush ou Perguntados. Neste sentido, $25 \%$ utiliza aplicações que pertencem ao âmbito das redes sociais. As aplicações do âmbito educativo ficam num nível de baixo uso por parte dos questionados (12\%) pelo que se pode apreciar que utilizam pouco os SmartPhones ou o Tablet para o estudo ou para o trabalho de determinados conteúdos, seja por desconhecimento ou porque consideram estes dispositivos tecnológicos como um jogo ou um método de entretenimento e diversão.

\subsection{Dimensão 3. Utilização de jogo vs utilização didática}

Por ordem de preferência, as utilizações que os estudantes questionados dão aos dispositivos móveis são: a) Conversar com os seus amigos e amigas (41\%), Jogos (38\%), Navegar pela Internet (21\%).

Entre os estudantes que dispõem de algum dispositivo móvel, quase a totalidade deles (94\%) têm aplicações descarregadas no seu SmartPhone ou Tablet.

Relativamente ao tipo de aplicações utilizadas, é como se pode comprovar, o WhatsApp (31\%), a App mais utilizada por utilizadores desta idade, permitindo-lhes manter. A seguinte aplicação mais utilizada é o Youtube (9\%), sendo o Instagram a aplicação que se encontra no terceiro lugar com $4 \%$ de estudantes. É a terceira aplicação mais utilizada por estes alunos (4\%). 


\section{Gráfico 2. Apps que os estudantes utilizam}

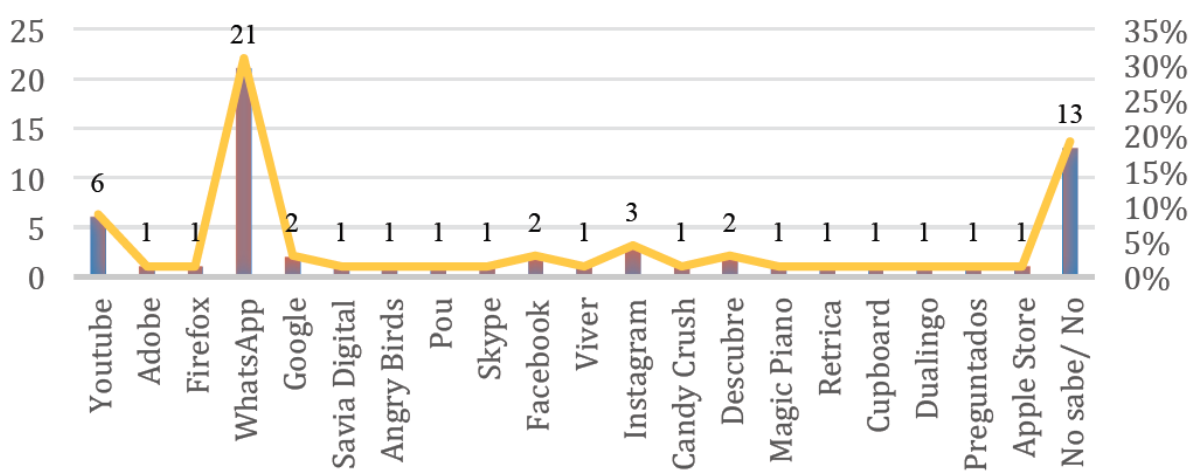

Definitivamente, destaca-se a utilização de aplicações de entretenimento frente à utilização de aplicações dedicadas a conteúdos curriculares entre os estudantes questionados.

\subsection{Dimensão 4. Atitude diante da utilização didática de dispositivos móveis}

De forma quase unânime (96\%), os estudantes submetidos à experiência declaram positivamente o seu desejo de poder trabalhar com dispositivos móveis dentro da sala. Neste sentido, existem claras preferências de matérias mais interessantes para o seu uso na sala. Deste modo, $32 \%$ dos questionados responderam que gostariam de trabalhar a Matemática com estes meios, seguido por $23 \%$ que se inclinam para as Ciências Sociais. 18\% decantam-se pelo Inglês, contra 14\% que afirmam que a disciplina de Línguas seria boa para ser trabalhada com o SmartPhone ou com o Tablet. As disciplinas de Música, Plástica e Ciências Naturais foram eleitas por um sujeito apenas.

65\% dos estudantes conhecem aplicações educativas, apesar de mais de metade deles declarar que a App criada para a investigação (Descubre Toledo) é a única com a qual trabalharam.

Relativamente à atitude demonstrada pelos estudantes diante da utilização da aplicação, assim que terminem a interação com ela, 37\% respondeu que a aplicação pareceu-lhes boa ou muito boa. Na percentagem semelhante de sujeitos, estes responderam que a aplicação lhes parece muito divertida, por isso, podem destacar que existe uma valorização muito positiva sobre a aplicação, tanto no âmbito lúdico quanto 
no âmbito educativo. Também foi valorizado o seu desenho com $18 \%$ dos sujeitos que estabeleceram a avaliação de que se tratava de uma aplicação muito bonita.

\section{Gráfico 3. Valorização da experiência da App}

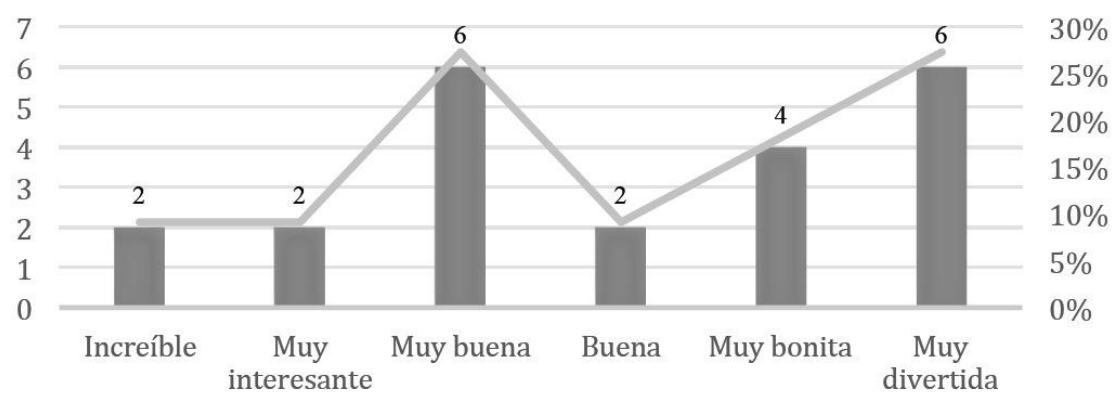

Em relação à utilização, 45\% dos sujeitos respondeu que, na hora de manipular a aplicação, encontrou uma dificuldade moderada, enquanto $41 \%$ respondeu que lhes pareceu fácil a interação com a aplicação. Um aspecto positivo que se pode destacar é que nenhum dos sujeitos que respondeu pensa ter sido difícil ou muito difícil interagir com a aplicação, pelo que se pode estabelecer que foi adequada para o nível e para a idade dos alunos e alunas do $5^{\circ}$ ano da Educação Primária.

Por último, fazemos eco do tipo de modificações que os estudantes assinalaram com vista a uma melhoria na aplicação. Encontramo-nos com a principal modificação que estes fariam, que é a de incluir mais conteúdos (36\%), em concreto, mais monumentos pertencentes a Toledo. Outras atendem a melhorias nos áudios (9\%), dispôr de mais atividades, incluir desenhos animados, que podem aparecer eles (os estudantes) na aplicação (5\%), aspecto que no se pôde estabelecer porque a maior parte dos pais não deram o seu consentimento. Por último, uma alta percentagem (36\%) respondeu que não era necessária alguma modificação ou melhoria relativamente à referida aplicação. 


\subsection{Corroboração das hipóteses}

Assim que ditos dados sejam analisados, procede-se à corroboração ou à refutação das hipóteses colocadas antes de começar o estudo:

- Como primeira hipótese, colocava-se que um número muito elevado de crianças entre os 10 e os 11 usam um SmartPhone ou um Tablet, o que no estudo é afirmado como correto, dado que a percentagem de $65 \%$, concretamente 44 alunos e alunas dos 68 questionados, possuem SmartPhone; e 78\% dos questionados, 53 alunos e alunas, possuem um Tablet.

- A segunda hipótese colocada, trata das aplicações que costumam utilizar estes sujeitos, e estabeleceu-se que, concretamente, utilizavam as aplicações para jogar ou conversar com os amigos, deixando de lado as funções que podem oferecer em relação ao estudo.

- Depois de levar a cabo o inquérito, pode afirmar-se que, a maior utilização dada pelos sujeitos a estes dispositivos tecnológicos, é jogar e conversar com os seus amigos e amigas, deixando de lado o âmbito educativo, ou seja, não os utilizam para o estudo de um determinado conteúdo. Apenas 29 dos 68 sujeitos responderam que utilizam o SmartPhone ou o Tablet para estudar.

- Como terceira hipótese, colocou-se que costumam utilizar estes dispositivos para jogar, para ouvir música e para contactar com os seus amigos através de alguma rede social. Em primeiro lugar, destaca-se que são utilizados, pela grande maioria, para jogar e para contactar com os seus amigos e amigas. No entanto, pelo outro lado, destaca-se que a funcionalidade de ouvir música não tem grande importância na utilização que fazem dos dispositivos tecnológicos (SmartPhone ou Tablet).

- Por último, em relação à quarta hipótese, podemos afirmar que a maioria dos alunos e das alunas que levaram a cabo este estudo declaram uma atitude positiva relativamente aos dispositivos tecnológicos, já que o feedback que recebem mediante estes dispositivos, ao trabalharem com conteúdos diferentes, levando a cabo atividades interativas, não é o mesmo que podem receber de outros recursos. 


\section{Conclusões e discussões}

A finalidade do nosso trabalho era que os estudantes do $5^{\circ}$ ano da primária se acostumassem à utilização de dispositivos tecnológicos, concretamente ao Tablet ou ao SmartPhone para o uso educativo. Para isso, trabalhou-se na dimensão didática, fazendo uso de conteúdos históricos e promoveu-se o trabalho de competência do uso das tecnologias. Como resultado, destaca-se que, graças à aplicação destes dispositivos, incentivou-se e motivou-se os alunos e alunas para que saíssem da situação habitual da sala na qual se encontram, e queria-se projetar uma nova forma de trabalho com este tipo de tecnologia para conseguir uma aprendizagem eficaz. Portanto, podemos afirmar que os objetivos propostos foram cumpridos. Assim, pôde saber-se com que fim os alunos e as alunas utilizam o SmartPhone ou o Tablet, comprovou-se a atitude que declaram ante o uso didático e conheceu-se qual o tipo de aplicações costumam utilizar quando estão com o seu SmartPhone ou Tablet.

À vista dos resultados obtidos, detalhamos as conclusões às quais chegamos:

1. A maioria das crianças de 10-11 anos dispõem de dispositivos móveis tipo SmartPhones e Tablets. Depois de analisar os resultados, obteve-se que, unicamente dois dos sujeitos questionados, não têm nem SmartPhone, nem Tablet, mas que a grande maioria conta ou com SmartPhone ou com Tablet para a sua utilização sempre que o desejarem. Pode ser afirmado que, quando os alunos trabalham com estes dispositivos tecnológicos, encontram-se mais receptivos e participativos, além de quererem trabalhar com mais ímpeto. Portanto, mostram uma atitude positiva quando fazem uso do SmartPhone ou do Tablet. Além disso, de acordo com Ramos, Herrera e Ramírez (2010), os recursos m-Learning e a utilização de dispositivos móveis apoiam os estudantes em estratégias que promovem o desenvolvimento das capacidades cognitivas como solução dos problemas, tomada de decisões, pensamento crítico, pensamento criativo e o aumento da sua motivação pelo trabalho que estão a levar a cabo.

2. A utilização educativa do SmartPhone ou do Tablet entre as crianças de 10-11 anos é escassa ou praticamente inexistente. Conseguiu-se comprovar que uma minoria 
utiliza estes dispositivos para estudar, no âmbito educativo. Ditos sujeitos costumam utilizar o SmartPhone ou o Tablet para aspectos diferentes do educativo. Por exemplo, utilizam-nos para: conversar com os seus amigos e amigas, jogar e navegar pela Internet. Por isso, intercedeu-se para que mudem a sua utilização ou incorporem a sua rotina ao utilizar estes dispositivos para trabalhar os conteúdos tratados na sala e que sejam meios através dos quais se possam realizar trabalhos e estudar conteúdos.

3. O tipo de aplicações em dispositivos móveis mais utilizadas entre as crianças de 10-11 estão relacionadas com jogos e com as redes sociais. Depois de analisar os resultados obtidos, pode testemunhar-se que uma grande maioria utiliza aplicações referidas a jogos, as quais oferecem feedback e entretêm, já que, por normal geral, têm um desenho atraente à vista. Também utilizam aplicações referidas às redes sociais, ou seja, aplicações nas quais podem manter conversas com os amigos e amigas, visualizar e subir fotografias, compartilhar experiências, etc. Em contrapartida, com a investigação levada a cabo por Cantillo Valero, Roura Redonda e Sánchez Palacín (2012), que estabelecem que as aplicações que os alunos e alunas utilizam e devem utilizar, são as que se relacionam com as competências que devem adquirir na educação primária. Contudo, em menor medida, utilizam as aplicações referidas no âmbito educativo. Por isso, com a criação desta aplicação e com a integração do SmartPhone e do Tablet na sala, promoveu-se a utilização deste tipo de tecnologias, com a intenção de aumentar a confiança dos pais para que não considerem como inimigo, nem o SmartPhone, nem o Tablet.

4. A utilização de aplicações educativas na aula produz uma melhoria nas competências TIC do estudante do $5^{\circ}$ ano da primária. Com a criação da aplicação e a posterior utilização na sala, aumentou-se o nível de motivação para trabalhar com estas tecnologias, bem como o nível de atenção e a forma de utilizar o SmartPhone e o Tablet. De acordo com Álvarez (2010), os docentes devem explorar ao máximo o potencial das TIC em relação às práticas pedagógicas para potenciar uma aprendizagem digital mais autónoma e flexível. Ainda, há que assinalar que as TIC facilitam o desenvolvimento de atividades de aprendizagem nas intervenções 
educativas onde se conseguem com eficiência os objetivos formativos previstos (MARQUÈS, 2005).

Dificuldades de implementação destes dispositivos tecnológicos na aula

Apesar de ser verdade que a implementação destes dispositivos na sala é muito positiva, ainda existem dificuldades na hora de trabalhar com eles. Isto pôde ser comprovado em aspectos como:

1. Escassez de dispositivos tecnológicos na aula. Para trabalhar com o SmartPhone ou com o Tablet, precisa possuir estes dispositivos no colégio e, atualmente, existem muitos centros nos quais não existem quadros digitais interativos, nem sequer sala Althia. Portante, trata-se de uma melhoria nas infra-estruturas para poder implementar estes recursos e trabalhar com eles na aula. Como bem afirma Cabero (2007), o acesso e os recursos necessários por parte do estudante, bem como a necessidade de uma infraestrutura administrativa e pessoal técnico de apoio, o custo da integração de dispositivos tecnológicos na sala e a necessidade de adaptar-se a novos métodos de aprendizagem, são incómodos aos quais hoje em dia temos que enfrentar nas salas.

2. Desconfiança por parte dos pais e escassez de conhecimentos por parte destes e dos professores. Na hora de levar a cabo o projeto, pediu-se aos pais que os seus filhos e filhas levassem o Tablet ou o SmartPhone para a sala de aula. Como alguns deles se opuseram, os respetivos filhos e filhas tiveram de utilizar dispositivos que não eram os seis para levar a cabo a atividade. Relativamente aos professores, o professor da sala é seguidor das TIC e, por isso, o trabalho foi desenvolvimento corretamente. No entanto, ao contrário, as outras tutoras do $5^{\circ}$ ano mostraram-se resistentes pois não utilizam as TIC como recurso, o que condicionou as possibilidades de contribuir para os processos de ensinoaprendizagem dos seus alunos e alunas com ferramentas que favorecem a inovação e complementam os já existentes. 
Limitações e contribuições práticas da experiência

A investigação apresentada possui uma série de limitações por tratar-se de um caso de estudo numa determinada classe e a nível reduzido, sem se poder generalizar os resultados a todas as crianças que tenham entre os 10 e os 11 anos de idade. Além disso, apesar do colégio possuir infraestruturas modernistas, os dispositivos tecnológicos com os quais conta são quadros digitais e computadores portáteis, deixando de lado os dispositivos, como o SmartPhone e o Tablet, pelo que os alunos tiveram de levar o material de casa e, no caso de não o possuir ou os pais se mostrarem contrários à proposta, teve de optar-se por trabalhar com dispositivos que não eram seus, mas sim de outros colegas.

Por outro lado, a documentação científica em redor do objeto de estudo ainda é escassa, sendo que a maioria vai direcionada a outros campos científicos, como o da medicina. Apesar disso, é verdade que existem trabalhos, como é o caso da criação de aplicações por parte de alunos e alunas e a sua posterior aplicação na aula, que ajudaram e beneficiaram o desenvolvimento deste trabalho.

Por último, tendo em conta a informação dada pelos diferentes meios, através dos quais este trabalho é sustentado, chegamos à conclusão de que, para poder implementar estes dispositivos tecnológicos na aula, necessita-se de uma mudança na imagem coletiva existente, de forma distorcida, entre os diferentes agentes educativos (docentes e pais). Assim que estas tecnologias, em conjunto com os dispositivos adequados, se encontrem na sala de forma normalizada, deverá passar-se a utilizá-los como um recurso educativo de inovação metodológica através do qual se podem estabelecer processos corretos de ensino-aprendizagem. Portanto, de acordo com Baena Jiménez (2008), se realmente pretende que as tecnologias sejam um instrumento educativo, deve prevenir uma autêntica transformação pedagógica na sala e, como consequência, uma transformação nos papéis dos professores e dos estudantes, com o objetivo de alcançar um nível maior de motivação e interesse de uns e dos outros em relação ao processo de ensinoaprendizagem. 


\section{Referências}

ALBION, Peter Robert.; TONDEUR, Jo; FORKOSH-BARUCH, Alona \& PEERAER, Jef. Teachers' professional development for ICT integration: Towards a reciprocal relationship between research and practice. Education and Information Technologies, 2015. Disponível em:

http://www.oerasia.org/images/files/twg3_manuscript_revised_clean.pdf. Consultado no dia 21 de maio de 2015.

ÁLVAREZ, Sergio. Uso de contenidos educativos digitales a través de sistemas de gestión del aprendizaje (LMS) y su repercusión en el acto didáctico comunicativo. Tese de Doutoramento, 2010. Disponível em: http://eprints.ucm.es/11631/1/T32372.pdf. Consultado no dia 12 de setembro de 2014.

ÁLVAREZ, Paula. \& O'SULLIVAN, Damien. (2015). Estándares Internacionales de Competencias Digitales: su Invaluable aporte en la educación del siglo XXI. Actas Virtual Educa 2013. Área 8: Modelos exitosos de educ@ción internacional: claves adaptables a otros contextos, 2015. Disponível em:

http://reposital.cuaed.unam.mx:8080/jspui/bitstream/123456789/3861/1/VE13.404.pdfCo nsultado no dia 23 de maio de 2015.

BAENA, Juan José. Las TICS: Un nuevo recurso para el aula. Innovación y experiencias educativas, n 13, 2008. Disponível em: http://www.csi-

csif.es/andalucia/modules/mod_ense/revista/pdf/Numero_13/JUAN_J_BAENA_1.pdf . Consultado no dia 24 de outubro de 2014.

CALERO, Julio. Los retos de la integración de las TICs en los procesos educativos. Límites y posibilidades. Perspectiva Educacional, v. 49, n. 1, 2010. p. 32-61.

CANTILLO VALERO, Carmen; ROURA REDONDA, Margarita y SÁNCHEZ PALACín, Ana . Tendencias actuales en el uso de dispositivos móviles en educación. La educ@ción digital magazine, n. 147, 2012. p. 1-21.

CLARO, Magdalena. Impacto de las TIC en los aprendizajes de los estudiantes. Estado del arte. CEPAL (Naciones Unidas): Santiago de Chile, 2010. Disponível em: http://www.ibertic.org/evaluacion/sites/default/files/biblioteca/2_impacto-ticsaprendizaje.pdf. Consultado no dia 14 de abril de 2015.

CAÑELLAS CABRERA Aries M. Impacto de las TIC en la educación: un acercamiento desde el punto de vista de las funciones de la educación. Quaderns digitals: Revista de Nuevas Tecnologías y Sociedad, 43, 2006. Disponível em: http://goo.gl/5gSljj. Consultado no dia 13 de abril de 2015.

EDUCALAB. Las competencias digitales del docente del siglo XXI. Disponível em: 
http://educalab.es/intef/tecnologia/competencia-digital/competencias-del-siglo-xxi Consultado no dia 23 de março de 2015.

FERNÁNDEZ MUÑOZ, Ricardo. Competencias profesionales del docente en la sociedad del siglo XXI. Organización y gestión educativa: Revista del Fórum Europeo de Administradores de la Educación (OGE), v. 11, n. 1, p. 4-7, 2009.

GALLEGO, Domingo, CACHEIRO, María Luz y DULAC, José. La pizarra Digital Interactiva como recurso docente. Teoría de la educación, v. 19, n. 2, pp. 127-145, 2009.

GÉRTRUDIX-BARRIO, Felipe y BALLESTEROS, Verónica. El uso de herramientas 2.0 como recursos innovadores en el aprendizaje de niños y niñas en Educación Infantil. Un estudio de caso de investigación-acción. EDUTEC, Revista Electrónica de Tecnología Educativa, 49, 2014. Disponível em http://edutec.rediris.es/Revelec2/Revelec49/n49_Gertrudix-Ballesteros.html

GRANADOS, Jorge Enrique. Las Tecnologías de la Información y la Comunicación en el Politécnico Colombiano Jaime Isaza Cadavid. Bogotá, 2005. Consultado no dia 12 de abril de 2015. Disponível em:

http://www.gestiopolis1.com/recursos2/documentos/archivodocs/ager/TICG7AL.pdf

HERNÁN MORA, Carlos. ¿Qué es el aprendizaje móvil?, 2010. Disponível em http://issuu.com/tacho/docs/presentaci_n_carlos_mora3. Consultado no dia 30 de janeiro de 2015.

HOFMANN, Joachim. Why Blended learning hasn't (yet) fulfilled its promises. Handbook of Blended Learning: Global Perspectives, local designs. San Francisco, CA. Pfeiffer, 2006.

INSTITUTO CRANDON. Ser docente en el siglo XXI: ensayos. Ediciones B Uruguay S.A: Montevideo, 2015.

KULIK, James A. Effects of Using Instructional Technology in Elementary and Secondary Schools: What Controlled Evaluation Studies Say. SRI International: Arlington, 2003. Disponível em:

http://www.ic.unicamp.br/ wainer/cursos/2s2004/impactos2004/Kulik_ITinK12_Main_Report.pdf. Consultado no dia 12 de abril de 2015.

LAURILLARD, Diana. Pedagogcal forms of mobile learning: framing research questions. In PACHLER, N. (Ed.). Mobile learning: towards a research agenda. London: WLE Centre, Institute of Education, 2007. p. 33-54.

LÓPEZ ESCRIBANO, Carmen. Contribuciones de la neurociencia al diagnóstico y tratamiento educativo de la dislexia del desarrollo. Revista de neurología, v. 44, n. 3 , 2007. p. 173-180. 
MARQUÈS GRAELLS, Pere. Claves para mejorar los aprendizajes integrando las tecnologías móviles en las clases, 2013. Disponível em http://goo.gl/qoD81y. Consultado no dia sexta-feira, 12 de Dezembro de 2014.

RAMOS, Ana Isabel; HERRERA, José Alberto y RAMÍREZ, Ma Soledad. Desarrollo de habilidades cognitivas con aprendizaje móvil: un estudio de casos. Comunicar, v. XVII, $n^{\circ} 34$, 2010. p. 201-209.

TRUCANO, Michael. Knowledge Maps: ICT in Education. InfoDev: Washington, 2003. Disponível em: https://www.infodev.org/infodev-

files/resource/InfodevDocuments_8.pdf. Consultado no dia 12 de abril de 2015.

VÁZQUEZ-REINA, Marta. M-Learning: aprender a través del móvil, 26 de enero de 2011. Disponível em:

http://www.consumer.es/web/es/educacion/otras_formaciones/2011/01/26/198521.php Consultado no dia 24 de março de 2015.

VALENCIA COBOS, Jorge y SAID HUNG, Elías. Análisis del uso de las TIC como herramienta de enseñanza-aprendizaje en los docentes del distrito de Barranquilla. Em: SAID, E. y GÉRTRUDIX, M. (Eds.) Actas del VII Simposio Las Sociedades ante el Reto Digital, 2014. p. 357-366. Disponível em:

http://www.icono14.es/files_actas/7_simposio/23_jorge_valencia.pdf. Consultado no dia segunda-feira, 23 de Março de 2015.

ZUGOWITKI , Vanina. El uso de las TIC en el aula incrementa la motivación de los alumnos, 29 de marzo de 2012. Disponível em: http://www.redusers.com/noticias/lautilizacion-de-las-tic-en-las-aulas-incrementa-la-motivacion-de-los-alumnos. Consultado no dia 21 de janeiro de 2015.

Recebido em: 02/11/2015 Aprovado em: 21/12/2015

Universidade do Estado de Santa Catarina - UDESC Programa de Pós-Graduação em Educação - PPGE

Revista Linhas

Volume 17 - Número 33 - Ano 2016 revistalinhas@gmail.com 